\title{
Cosme de Farias e os Capoeiras na Bahia: Um Capítulo de História e Cultura afro-brasileira
}

\author{
Josivaldo Pires de Oliveira (Bel)
}

\begin{abstract}
Resumo: Na primeira metade do século XX, os capoeiras (agentes culturais de uma das mais representativas manifestações afro-brasileiras) se envolviam com a justiça baiana e contavam com o rábula Cosme de Farias para os defender. O presente artigo aborda, a partir de processos criminais e notícias de jornais, a atuação do referido rábula na defesa dos capoeiras que se envolviam com a justiça em Salvador neste período. Entre estes se encontram nomes importantes da história da capoeira na Bahia, a exemplo de "Pedro Porreta" e "Chico Três Pedaços".

Palavras-chave: Capoeira; Bahia; Cosme de Farias
\end{abstract}

Abstract: In the first half of the twentieth century, capoeira (the cultural one of the most representative manifestations african-Brazilian) were involved with the justice of Bahia and were much shyster Cosme de Farias to defend them. This article discusses, from criminal cases and newspaper reports, the performance of that shyster defense of the barns that were involved with justice in El Salvador during this period. Among these are names in the history of capoeira in Bahia, like "Pedro Porreta" and "Chico Três Pedaços."

Key-words: Capoeira; Bahia; Cosme de Farias.

Alguns, cujos nomes aqui se encontram e que, por razões óbvias deixo sem destaque, foram, em seu tempo, motivos de terror. Suas histórias por muitos homens de idade avançada lembradas devem estar registradas nos arquivos policiais.

Mestre Pastinha (1889-1981)

A capoeira, prática cultural de matrizes africanas, tem se destacado nas últimas décadas como objeto de investigação das ciências humanas e sociais, e uma das principais manifestações reveladoras da dinâmica diaspórica das culturas africanas no Brasil. Sua trajetória pode ser acompanhada a partir da literatura já produzida por antropólogos e historiadores que tiveram como ponto de partida para suas investigações as crônicas e memórias que registraram os costumes dos africanos no Brasil, em especial nas cidades do Rio de Janeiro, Salvador e Belém do Pará.

Os registros documentais mais precisos sobre a Capoeira no Brasil remetem ao século XIX. Essas fontes apontam ser esta praticada predominantemente pelos africanos na primeira metade do referido século. Registros de prisões de escravos e libertos nas ruas de grandes centros como o Rio de Janeiro, Corte Imperial, representam a principal documentação de constatação do universo africano da Capoeira. A partir de meados do século XIX, a documentação encontrada pelos pesquisadores permite evidenciar a

${ }_{1}^{1}$ Professor do Departamento de Ciências Humanas da Universidade do Estado da Bahia/Campus VI. Doutorando em Estudos Étnicos e Africanos na Universidade Federal da Bahia. Coordenador do Malungo Centro de Capoeira Angola-BA. 
experiência dos capoeiras em outras localidades, além da Corte Imperial, inclusive alcançando as três primeiras décadas do século XX.

Entre as diversas abordagens que caracterizam os estudos da capoeira no Brasil, encontra-se o interesse pelo universo das ruas e do cotidiano dos capoeiras evidenciando a dinâmica de suas relações sociais e de poder. Este é o caso da história social dos capoeiras na Bahia da primeira metade do século XX. Na epígrafe acima, o Mestre Pastinha (mentor da capoeira angola) chama a atenção para o universo da criminalidade que envolvia os capoeiras, indicando os arquivos policiais como fonte de pesquisa. De fato, o velho mestre tinha razão.

A bibliografia da capoeira como manifestação da cultura afro-brasileira, portanto, da diáspora africana no Brasil, é extensa. Muito se têm estudado sobre o seu aspecto lúdico-percusivo e musical, assim como a organização de centros e escolas para sua aprendizagem. Nestes trabalhos também se investe bastante na busca do mito de origem da capoeira: brasileira ou africana? Entretanto, aqui dedicarei esforços para entender os bastidores das relações sociais que os agentes da capoeiragem experimentaram com o conjunto maior da sociedade. Ou seja, este é um trabalho que se enquadra no que se pode definir como uma micro-história dos capoeiras na Bahia. Portanto, aqui serão abordadas questões relacionadas à cultura e criminalidade no cotidiano dos capoeiras na capital baiana, na primeira metade do século XX.

\section{Capoeira, cultura e criminalidade}

A repressão aos capoeiras no início da República, assim como de outras manifestações afro-brasileiras, era respaldada pelo Código Penal de 1890, e, muitos acreditavam que a perseguição policial daria fim, de uma vez por todas, aos "ajuntamentos de pretos" e seus degradados sociais conhecidos por capoeiras, como a sociedade de então os classificavam, especialmente na capital federal do início do século XX. Foi tão dura a repressão que se chegou a acreditar que o Rio de Janeiro deste período não era mais lugar para os capoeiras. Entretanto, os temidos capoeiras ainda incomodariam por mais algum tempo e conquistariam, inclusive, o seu lugar de protagonista nos motins políticos, sociais e no universo de práticas simbólicas afro-brasileira, não apenas na capital da República, assim como em outras regiões a exemplo de Salvador, capital da Bahia.

O cotidiano dos capoeiras na capital baiana, na primeira metade do século XX, era marcado pelas relações estabelecidas no universo das ruas. Essas ruas eram concebidas pelas elites soteropolitanas como espaço privilegiado para a criminalidade que tinha origem 
nos comportamentos anti-sociais das camadas populares, a exemplo da vagabundagem. Para se compreender o universo social em que viviam os capoeiras neste período, como lembrava o Mestre Pastinha, é necessária uma reconstituição histórica de aspectos da dinâmica dessas ruas e do cotidiano de seus principais agentes sociais: homens e mulheres das camadas populares. Era comum os noticiários publicarem manchetes como "Campanha contra a gatunagem", "Campanha contra a vagabundagem", "O policiamento das ruas", e outros mais. Nessas notícias constavam informações sobre os capoeiras, por mais que nem sempre fossem identificados como tais. Os indivíduos, nas referidas manchetes, eram identificados por alcunhas um tanto quanto depreciativas a exemplo de "desordeiros", “vagabundos", "faquistas", "valentes" e "capadócios". 2 Talvez este último denotasse de forma mais precisa o tipo social dos capoeiras que viviam e conviviam nas ruas da velha cidade da Bahia. Esses indivíduos não apenas repugnavam as camadas abastardas da sociedade, mas também despertava certa admiração muito bem ensaiada na poesia de Manoel Rosentino:

Adoro o capoeira petulante/O cabra debochado/O terror do batuque/O desordeiro/ Que anda sempre de compasso ao lado (...)/Adoro o capadócio da Bahia/Esse eterno patife/Que gosta de bater numa pessoa/Como quem bate beef? ${ }^{3}$

Segundo Manuel Querino, o capadócio era, na Bahia de outrora, o tipo social do capoeira. ${ }^{4}$ Protagonistas das ruas, viviam expostos às condições de sobrevivência que as mesmas lhes ofereciam, portanto, estavam sujeitos a cometerem delitos das formas mais variadas possíveis, desde as pequenas contendas que ocorriam nas ruas, até os grandes conflitos envolvendo interesses políticos e relações de poder. Experimentavam os capoeiras, o universo da criminalidade, experiências essas, marcadas por resistências explorando as várias possibilidades de sobrevivência do ser capoeira na Salvador republicana. Denominados capadócios, dentre outros adjetivos de semelhante conduta, os capoeiras baianos responderam junto ao Tribunal do Júri da Comarca da Capital muitos processos criminais, mas poucos desses capoeiras ficavam na detenção, contavam com o famoso rábula Cosme de Farias para defendê-los, um pouco dessa história é o que se encontra aqui.

\footnotetext{
2 Por "capadócio" entendia-se o "indivíduo de maneiras acanalhadas; parlapatão, fanfarrão; trapaceiro, charlatão”. FERREIRA, Aurélio Buarque de Holanda. Pequeno dicionário brasileiro da língua portuguesa - Ilustrado. 11 ed. Rio de Janeiro: Gama/Civilização Brasileira, 1971, (não consta número de páginas).

${ }^{3}$ Citada por MOURA, Jair. "A sinonímia popular da capoeiragem”. In: Capoeira: ginástica da resistência. Revista da Babia, v. 32, n 33, Julho de 2001, p. 85.

${ }^{4}$ QUERINO, Manoel. Babia de outrora. Salvador: Livraria Econômica, 1916.
} 


\section{Notícias sobre o último rábula da Bahia: Cosme de Farias}

Em uma das várias seções do Tribunal do Grande Júri na Cidade do Salvador no ano de 1895, um juiz de nome Vicente Tourinho perguntou à platéia quem poderia defender um negro acusado de ter roubado a importância de 500 réis e que fora abandonado pelo seu advogado à beira do Júri. Quando "um rapazola mulato, traços grosseiros e cara de menino" se pronunciou aceitando o desafio, sem ao menos conhecer as peças do processo e o acusado. Depois de uma rápida leitura nos autos, o réu Abel Nascimento foi absolvido. O argumento da defesa foi nada mais que: "a falta de oportunidade na vida o conduzira ao crime". 5

O citado "rapazola mulato" de "traços grosseiros" era o Major Cosme de Farias, considerado o último rábula da Bahia e um dos advogados que mais ganhou causas consideradas perdidas. O Rábula também chamado Provisionado era o advogado que, não possuindo o bacharelado em Direito obtinha a autorização da entidade de classe, podendo assim pleitear o juizo. ${ }^{6}$ Cosme de Farias tinha apenas o curso primário, entrtetanto, atuou durante sua trajetória de vida em mais de 30 mil processos judiciais, foi "apontado como o campeão de habeas-corpus da Bahia, quiçá do país". ${ }^{7}$ O título de "Major" foi conseqüente de uma homenagem prestada pelo tenente Pedro Celestino Brandão e outros amigos quando lhe presentearam com uma patente do $224^{\circ}$ Batalhão de Infantaria da Guarda Nacional, em 1909. Vale ressaltar que neste período o título podia ser comprado, entretanto, o prestígio de Cosme de Farias lhe garantiu a aquisição do mesmo sem nenhum custo.

\footnotetext{
${ }^{5}$ CELESTINO, Mônica. “Cosme de Farias: advogado dos pobres”. In: Memórias da Babia. Salvador: Empresa Baiana de Jornalismo S. A., 2002, v. 1, p. 10. Alem dessa referência outras informações sobre a vida de Cosme de Farias pode ser encontrada em CELESTINO, Mônica. Réus, analfabetos, trabalhadores e um Major - a inserção política e social do parlamentar Cosme de Farias em Salvador. Salvador: UFBA, 2005. Dissertação de Mestrado.

${ }^{6}$ O sistema de Rábula foi extinto nas décadas de 1960 e 1970, quando a advocacia passou a ser prerrogativa exclusiva dos bacharéis em Direito.

${ }^{7}$ CELESTINO, Mônica. “Cosme de Farias: advogado dos pobres”, p. 10-11.
} 


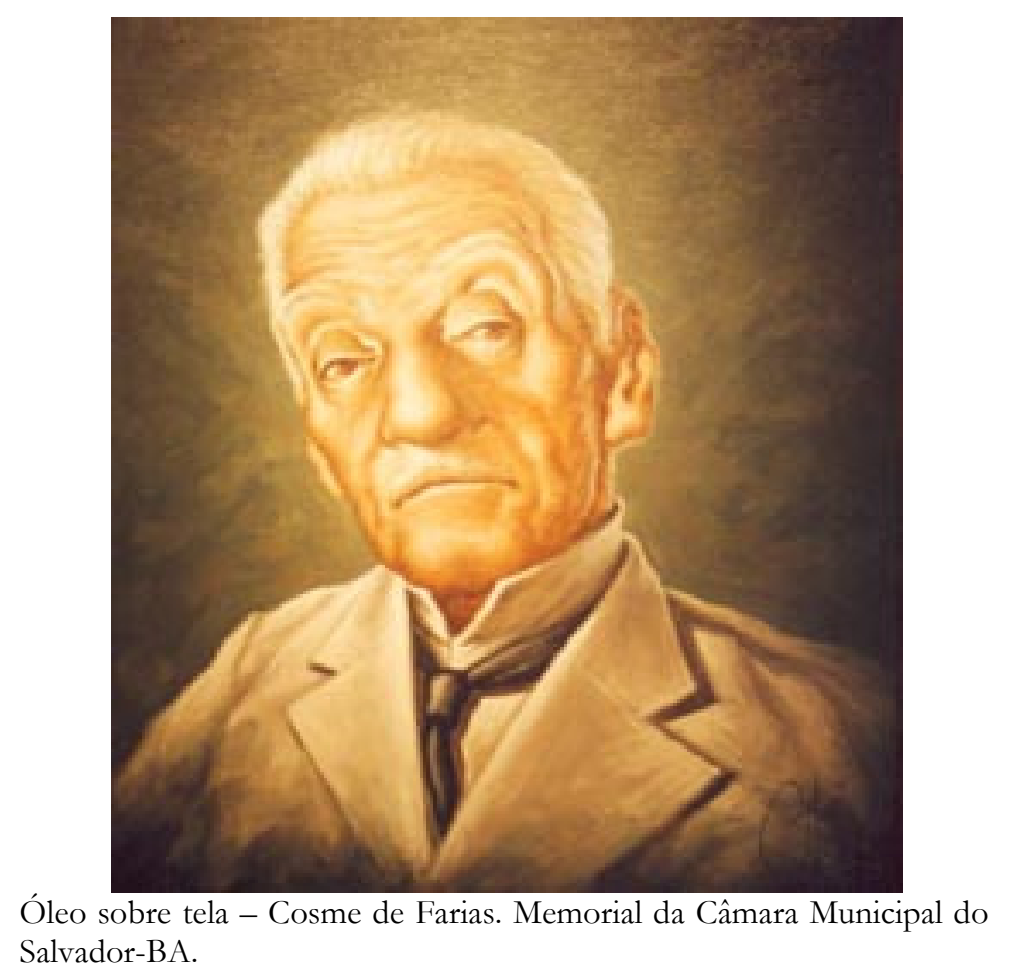

Nasceu no dia 02 de abril de 1875, em São Tomé de Paripe, subúrbio de Salvador, então Província da Bahia, filho de Paulino Manuel e Júlia Cândida de Farias, cursou apenas o primário. Seria o bastante para se tornar vereador, deputado estadual, ativista social tendo, como rábula, defendido "mais de 30 mil ladrões, prostitutas, bicheiros, homicidas, homens e mulheres caluniados, pobres que mofariam na cadeia sem dar a sua versão dos fatos". Muitos desses "criminosos" ou ludibriados réus defendidos por Cosme de Farias eram capoeiras. Em grande parte dos documentos que encontrei na pesquisa que deu origem ao livro No tempo dos valentes, o Major aparecia como autor de pedido de soltura e habeas-corpus em favor de indivíduos identificados como capoeiras. ${ }^{9}$ Os casos que se seguem ilustram a prática do rábula na defesa de capoeiras que comprovadamente se envolveram em conflitos de rua com diferentes proporções, gerando assim problemas com a justiça. Desde assassinatos de grande repercussão como foi o caso do capoeira Bastião, até as pequenas contendas da vida diária que marcaram a experiência de vida dos capoeiras Pedro Porreta e Chico Três Pedaços, o Major Cosme de Farias era requisitado como o rábula dos capoeiras.

\section{"Scenas de sangue": o crime do Saldanha e o capoeira Bastião}

\footnotetext{
${ }^{8}$ Idem, p. 8.

9 OLIVEIRA, Josivaldo Pires de. No tempo dos valentes: os capoeiras na cidade da Babia. Salvador: Quarteto, 2005.
} 
"Scenas de sangue" foi o título que acompanhou algumas manchetes publicadas no Jornal de Notícias da capital baiana, entre dezembro de 1914 e janeiro de 1915. Através dessas manchetes o Jornal de Notícias mantinha seus leitores informados sobre uma grande chacina que havia ocorrido na Rua Saldanha da Gama, no centro antigo da cidade, atual bairro do Pelourinho. Tratava-se do assassinato de dois marinheiros, entre os acusados os capoeiras Pedro Mineiro, Bastião e Branco:

\begin{abstract}
Disse-nos um marinheiro do destroyer Piauhy, surto em nosso porto, que se achava na rua do Saldanha, com outros companheiros, conversando com umas mulheres, alli residentes, quando se aproximaram do grupo os individuos Pedro Mineiro, Sebastião de tal e Fuão Branco, os quaes, depois de ligeira troca de palavras, sacaram dos revolvers, disparando contra elles.

Foram rapidos os movimentos.

Sahiram alcançados pelos projectios os marinheiros José Domingos da Silva e Francisco Orlando Wanderley, os quaes, sentindo-se feridos, correram cahindo o primeiro na porta do prédio n. 6 a rua do Saldanha, e o segundo na porta da "Pharmacia Independência", á rua Dr. Seabra. ${ }^{10}$
\end{abstract}

Infelizmente não encontrei os autos do inquérito policial para que eu pudesse ter informações mais precisas sobre o desenrolar do processo judicial. Mas, as notícias de jornais permitiram lançar algumas interpretações sobre o que ocorreu no Saldanha, pois famosos capoeiras estavam envolvidos. Pedro Mineiro por exemplo é um dos mais conhecidos da memória histórica da capoeira da velha Bahia. Entretanto, acompanhava Pedro Mineiro, os capoeiras Branco e Bastião, acusados no processo como autores da chacina. ${ }^{11}$ Bastião parece ter sido beneficiado pelos filantrópicos serviços do rábula dos capoeiras, o Major Cosme de Farias.

\title{
IMPRONUNCIA E SOLTURA
}

Anti-hontem, á tarde, foi posto em liberdade Sebastião Pereira de Almeida, visto ter sido impronunciado pelo dr. Vergne de Abreu, ilustre juiz de direito da $1^{\text {a }}$ Circumscripção Criminal.

Este indivíduo que se achava recolhido á Casa de Correção e teve como defensor o major Cosme de Farias, era apontado como um dos auctores do assassínio de dois marujos do caça-torpedeiro Piauby, facto que teve logar há cerca de 3 mezes, na rua Saldanha.

Aquelle digno juiz assim procedeu devido á inesistencia absoluta de provas, nos autos, que denunciassem a criminalidade do accusado. ${ }^{12}$

\footnotetext{
${ }^{10}$ Jornal de Notícias, 28/12/1914, p. 2.

11 Alguns pesquisadores já se dedicaram ao caso de Pedro Mineiro e a chacina do Saldanha, entretanto nenhum de nós encontrou os autos do processo criminal. O acompanhamento do processo pode ser feito através do Jornal de Notícias que publicava os resumos das seções do Tribunal do Júri. Diferentes abordagens sobre o referido caso pode ser acompanhado em OLIVEIRA, Josivaldo Pires. No tempo dos valentes, op. cit. e DIAS, Adriana Albert. Mandinga, manha \& malícia: uma história sobre os capoeiras na capital da Babia (1910-1925). Salvador: EDUFBA, 2006 e PIRES, Liberac Cardoso Simões. A capoeira na Babia de Todos os Santos: um estudo sobre cultura e classes trabalhadoras (1890-1937). Tocantins: NEAB/ Grafset, 2004.

12 Gazeta do Povo, 24/03/1915, p. 2.
} 
Sebastião Pereira de Almeida era o nome do capoeira Bastião, companheiro de Pedro Mineiro, juntamente com o qual se envolveu no conflito referido na notícia. Em seu livro Capoeira Angola, Mestre Pastinha faz uma relação dos antigos capoeiras. Nesta relação aparecem os nomes de Bastião, acompanhado de Pedro Mineiro e Branco o que comprova que havia uma relação entre esses capoeiras e insinua a possibilidade de Cosme de Farias ter atuado na defesa dos outros não identificados na documentação que tive acesso. ${ }^{13}$ Pastinha não detalha informações sobre eles, o que poderia ajudar na interpretação do caso, pois ampliou o número das vítimas com o falecimento de Pedro Mineiro, por conta de ferimentos sofridos na delegacia durante seu interrogatório sobre o assassinato dos marinheiros. ${ }^{14}$ Ressalte-se também que esses capoeiras foram acusados pela imprensa de serem secretas da polícia.

O grau da acusação contra Bastião não era pouco, pois se tratava de um crime contra marinheiros de um torpedeio nacional, entretanto o recurso utilizado por Cosme de Farias foi infalível. Por mais grave que tenha sido o crime do Saldanha e a acusação, o capoeira Bastião estava em liberdade e ele não foi o único envolvido neste caso que usufruiu das habilidades do rábula. O jornal Gazeta do Povo em edição de 14 de fevereiro de 1915 informou para os seus leitores que o Major havia conseguido uma ordem de hábeas corpus em "favor de Conrado José dos Santos, preso na correção e indigitado como um dos personagens que tomara parte no conflito da rua do Saldanha e que teve como resultado a morte de 2 marinheiros do caça-torpedeiro Piauby." 15

A “inesistencia absoluta de provas" que denunciasse o crime do qual o réu era acusado foi o seu argumento. Bastião havia sido denunciado pelo dr. Clóvis Spínola, promotor público da Primeira Circunscrição Criminal, como incurso no art. $294 \int 2^{\circ}$ do Código Penal, o qual pune o crime de morte. A penalidade do parágrafo segundo é de "prizão cellular de seis a 24 annos". ${ }^{16}$ Assim, escapou o Bastião de cumprir uma árdua pena, graças ao pedido de habeas-corpus emitido pelo rábula dos capoeiras.

Uma das peculiaridades do Major Cosme de Farias era o "componente emocional", “preferia o abalo psicológico dos acusadores do réu, dos jurados e da audiência, ao aparato

\footnotetext{
13 PASTINHA, Mestre. Capoeira angola. Op. cit. p. 24.

14 Acompanhei este caso pelos seguintes periódicos: Jornal de Notícias, Diário de Notícias e Gazeta do Povo. Os jornais publicaram documentos importantes a exemplo dos ofícios do comandante de corveta do Torpedeiro Pyauí e do chefe de polícia Álvaro Cova, os quais me serviram como fontes para analisar o caso. Ver OLIVEIRA, Josivaldo Pires. No tempo dos valentes, op. cit. Ver o capítulo intitulado: "De capadócios a agentes culturais".

15 Gazeta do Povo, 14/02/1915.

${ }^{16}$ CODIGO PENAL DOS ESTADOS UNIDOS DO BRASIL. (Comentado por Oscar de Macedo Soares). Rio de Janeiro: Garnier, 1904, p. 439-440.
} 
jurídico, da lógica forense e dos preceitos legais". "Um outro elemento muito recorrente em suas elaborações era a negação da razão do indivíduo no momento em que cometeu o crime. Este foi, inclusive, o argumento que utilizou em defesa do capoeira Pedro Porreta, outro nome da galeria dos imortais da capoeiragem baiana.

\section{Em defesa do valente Porreta}

Pedro Porreta é um dos capoeiras que mais apareceram nas colunas policiais dos jornais que circulavam na capital baiana nas décadas de 1930 e 1940. Envolvido com a zona de meretrício e desordens das ruas de Salvador Porreta já afugentou muitas patrulhas de policiais não sendo poucas as vezes que foi encarcerado. Para se ter uma idéia da fama de valentão que lhe cercava Waldeloir Rego em seu livro Capoeira Angola, lembra que quando uma criança parecia ser muito agressiva com a outra, na represália sua mãe perguntava se era Pedro Porreta. ${ }^{18}$ De fato, esse capoeira deixou rastros na documentação histórica que o denuncia como sendo um indivíduo muito perigoso, um capadócio que não aliviava nem mesmo quem dividia o teto com ele: ou seja, a própria companheira.

No dia 6 de maio de 1931, Pedro Porreta se desentendeu com sua companheira Josepha Alves de Araújo à porta de uma venda, situada nas proximidades da Rua da Assembléia, no distrito da Sé. Porreta agrediu a sua companheira que tombando ao chão teve o rosto seriamente machucado. Efetuada a prisão do agressor, o mesmo foi denunciado pelo promotor público da Primeira Circunscrição Criminal, incurso no art. 303 do Código Penal, em vigência, por crime de lesões corporais:

\footnotetext{
Aos seis dias do mez de Maio de mil novecentos e trinta e um, nesta capital do Estado da Bahia, na delegacia da Primeira Circumscripção Policial onde se achava o Doutor Tancredo Teixeira da Silva (...) pelo Doutor delegado lhe foi perguntada.

Como deu-se o facto do qual resultou o ferimento que apresenta. Respondeu que amasiada com Pedro Celestino dos Santos, conhecido por "Pedro Porreta", há mais de dois annos ao chegar a respondente na venda para comprar cem reis de (ileg.), cerca de dezoito horas, onde este já estava, reclamou porque ella não tinha entregue a roupa lavada e ella respondendo que depois entregava, elle deu-lhe uma bofetada e ella cahindo foi com a cara sobre as pedras ferindo-a; que o seu offensor é conhecido como desordeiro e tem sido preso diversas vezes; ${ }^{19}$
}

O trecho acima foi extraído dos autos de perguntas feitas a Josepha Alves de Araújo, vítima de espancamento de Pedro Porreta. Nele a vítima denuncia que seu companheiro e "offensor é conhecido como desordeiro e tem sido preso diversas vezes

\footnotetext{
${ }^{17}$ CELESTINO, Mônica. “Cosme de Farias...”. Op. cit., p. 11.

${ }^{18}$ REGO, Waldeloir. Capoeira angola: ensaio sócio-etnográfico. Salvador: Itapoã, 1968, p. 266.

19 APEB: Processo crime de Pedro Celestino dos Santos, vulgo "Pedro Porreta". Seção Judiciária, est. 210, cx. 220 , doc. 1 , p. 5.
} 
pela polícia". De fato, os jornais que circulavam na cidade de Salvador nas primeiras décadas do século XX, registraram uma série de conflitos envolvendo Pedro Porreta inclusive contra policiais e prostitutas, portanto não teria o valente capoeira um grande currículo para argumentar a sua defesa. ${ }^{20}$ Mas não foi preciso, alguém faria isto por ele. $\mathrm{O}$ termo de resposta do júri que o absolveu utilizou a seguinte argumentação: "o réu no acto de commetter o crime achava-se em estado de completa perturbação de sentido e de inteligência". ${ }^{21}$ Curiosamente, em nenhum momento da acusação e dos autos de perguntas do processo ele foi identificado como sendo portador de algum tipo de doença ou de qualquer limitação que caracterizasse o argumento do júri.

O rábula dos capoeiras novamente entra em ação, desta vez livrando Pedro Porreta da acusação de crime de lesão corporal. A negação da legitimidade do crime pela acusação de insanidade mental do réu era uma marca de Cosme de Farias e funcionou muito bem no caso de Pedro Porreta. Quanto a Josepha Alves de Araújo, companheira e vítima do notório capadócio, foi encaminhada para a enfermaria da Assistência Pública.

Interessa agora analisar o argumento de defesa do rábula e absolvição do réu frente às acusações da promotoria, segundo peças do próprio inquérito policial. $\mathrm{O}$ documento consultado sugere não haver dúvidas da responsabilidade do crime cometido pelo notório capoeira, como bem registrou o auto de prisão em flagrante delito:

Compareceu Milchiade Correia de Almeida (...). Compromissado na forma da lei, disse que as dezoito horas e poucos minutos procedeu em flagrante delicto o individo de nome Pedro Celestino dos Santos, vulgo "Pedro Porreta", na occasião em que acabava de ferir uma mulher de nome Josepha Alves de Araújo, na rua da Assembléia, districto da Sé, dentro do armazém número trinta e oito, logo, sendo testemunhas os seus collegas de número cento e vinte e nove e cento e cessenta e cinco, não sabendo pela offendida que assim tenha procedido porque ella sendo sua amasia não tinha preparado a comida, durante o dia, sendo a offendida conduzida para a assistência Publica (...). Passando o Doutor Delegado a interrogar o condenado Pedro Celestino dos Santos, conhecido por "Pedro Porreta", com vinte e seis annos de idade, solteiro, natural deste Estado, carregador, residente a rua do Saboeiro em número vinte e quatro, do districto da Sé; não sabendo ler nem escrever, disse que sua amasia Josepha estava bebendo na venda á rua da ajuda em vez de cuidar de lavar a sua roupa e depois da discusão deu-lhe um murro e esta caindo bateu com a cara nas pedras ferindo-se, sendo logo preso por guardas civis e conduzido para esta Delegacia. $^{22}$

Milchiade Correia de Almeida foi o guarda civil responsável pela autuação e prisão de Pedro Porreta (contando obviamente com a ajuda de outros policiais). O capoeira foi autuado em flagrante delito e confirmou na "forma da lei" a agressão exercida contra sua

\footnotetext{
${ }^{20}$ Ver OLIVEIRA, Josivaldo Pires de. No tempo dos valentes, op. cit. Capítulo 2: "Sobrevivendo nas ruas".

${ }^{21}$ Idem, p. 7.

22 Processo crime movido contra Pedro Celestino dos Santos, vulgo "Pedro Porreta", em 1931. APEB: Seção Judiciária: Est. 210, cx. 220, doc. 1, p.6.
} 
amásia. Em depoimento, confirmou ter agredido Josepha com "um murro e esta caindo bateu com a cara nas pedras ferindo-se". Portanto, seria ele um réu confesso.

Pedro Porreta acusou sua companheira de estar "bebendo na venda" ao invés de "lavar a sua roupa". Em seu depoimento, a acusação muda de foco e o mesmo tenta justificar a sua ação. Pedro passou a ser vítima e Josepha ré, pois não é digno de uma "mulher de bem" beber na venda e não cumprir com o seu papel de dona de casa: fazer a comida e lavar a roupa de seu companheiro. Identifica-se aí a legitimação dos papéis sociais. Josepha quebrou com a norma de comportamento feminino, ou seja: a mulher deveria obedecer ao marido e se limitar ao espaço doméstico. Vale ressalta que a rua era considerada um espaço eminentemente masculino e com ele eram tecidas as relações que buscavam a supremacia do masculino sobre o gênero feminino em um contínuo processo de legitimidade do poder do macho. ${ }^{23}$

Não está em discussão se Pedro Porreta tinha razão em relação às acusações que fez a Josepha. O certo é que não foi Josepha a acusada de espancamento e incursa no art. 303 do Código Penal, e sim Pedro Porreta. Entretanto, o agressor da pobre mulher foi absolvido e em menos de um mês estava em liberdade, como ficou evidente no pedido de soltura, assinado pelo rábula dos capoeiras, Major Cosme de Farias:

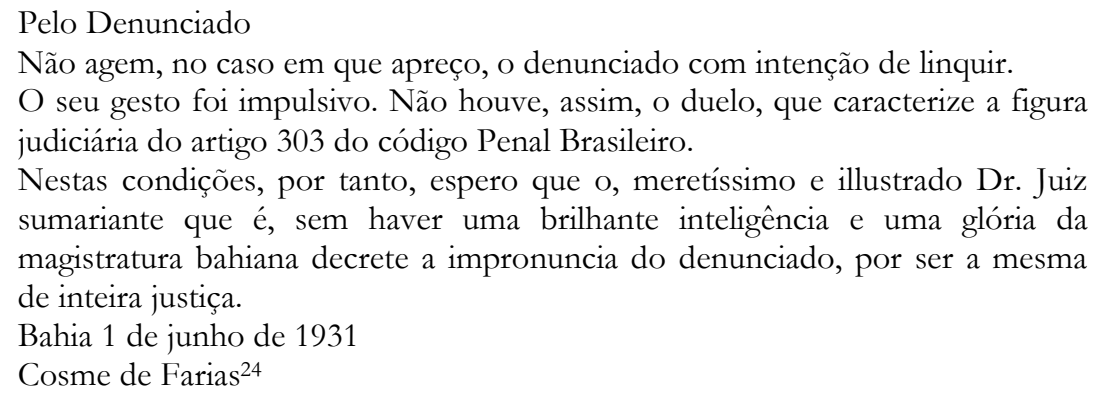

O argumento de Cosme de Farias, "pelo denunciado", foi a não caracterização da figura jurídica do art. 303 do Código Penal, ou seja, o acusado não tinha a intenção de ferir a vítima. Entretanto, em documento endereçado ao juiz da referida Circunscrição Criminal, o rábula utilizou um recurso eficiente, enalteceu exacerbadamente a pessoa do magistrado insinuando ser ela um símbolo da justiça baiana. Foi o bastante. Pedro Celestino dos Santos, vulgo Pedro Porreta, acusado do crime de lesões corporais, foi absolvido enquanto sobre a sua vítima, não sabemos em que situação de saúde ficou.

\footnotetext{
${ }^{23}$ Sobre relação de gênero e a noção de "poder masculino" ver o interessante ensaio de SAFFIOTI, Heleieth I. B. O poder do macho. São Paulo: Moderna, 1987.

24 Idem, p. 30.
} 
O termo de resposta do júri que absolveu Pedro Porreta dizia que "o réu no acto de commetter o crime achava-se em estado de completa perturbação de sentido e de inteligência". ${ }^{25}$ Como já observado, essa era uma característica peculiar de Cosme de Farias, ele influenciou o júri a tal decisão. A soma de valentes capoeiras defendidos pelo Major ainda iria acrescentar os casos envolvendo o capadócio que respondia pela alcunha de Chico Três Pedaços.

\section{Absolvendo o temível capoeira Três Pedaços}

Consta da tradição oral que João Francisco Pires foi vitima de uma emboscada arquitetada por um capoeira de nome Matatú. Ao tentar surpreender João à golpes de faca teve a mesma quebrada em três pedaços quando perfurava o corpo do capoeira, a partir de então João Francisco Pires ficou conhecido como Três Pedaços, ou melhor Chico Três Pedaços. ${ }^{26}$ Foi ele um dos valentes capoeiras que ao ter problemas com a justiça podia contar com o rábula dos capoeiras, o Major Cosme de Farias.

Na noite de 23 de julho de 1927, à Rua das Flores, distrito da Rua do Paço, na cidade do Salvador, foi preso em flagrante delito o indivíduo João Francisco Pires, conhecido por Três Pedaços, acusado de ferir com uma cabeçada a José Raymundo dos Santos. ${ }^{27} \mathrm{Na}$ versão da provável vítima, Três Pedaços teria entrado no estabelecimento comercial de nome "Café Para Todos", situado naquela localidade, e pedido um pouco de café, o que lhe foi servido. Logo em seguida, o referido capoeira teria proferido obscenidades, o que não foi do agrado de José Raymundo dos Santos, servidor daquele estabelecimento. Ao repelir, segundo ele, o comportamento de Três Pedaços, foi agredido pelo mesmo, tendo seus lábios atingidos por uma violenta cabeçada, golpe típico da prática dos capoeiras. Naquele instante teria comparecido uma praça de polícia e conduzido o agressor à Delegacia da Segunda Circunscrição. ${ }^{28}$

A versão do acusado foi outra completamente diferente. Três Pedaços negou a agressão a ele atribuída.

O acusado declarou que a noite de 23 de julho entrou no "Café Para Todos", a rua das Flores, afim de tomar café e que ao encontrar-se alli com um seu conhecido de nome "Matta Escura" com este teve uma discussão, ultimada com a retirada do mesmo Matta Escura; que, quando se achava fora do "Café

\footnotetext{
${ }^{25}$ Idem, p.7.

${ }^{26}$ REGO, Waldeloir. Capoeira angola: ensaio sócio etnográfico, p. 266.

${ }^{27}$ Contam que o apelido "Três Pedaços" tem origem em um conflito entre Chico e um outro capoeira de nome "Matatu", quando este armou-lhe uma emboscada e ao feri-lo com uma facada no peito, essa quebrouse em três, daí o apelido Chico Três Pedaços. Sobre este caso ver REGO, Waldeloir. Capoeira angola... Op. cit. p. 266.

28 Processo crime movido contra João Francisco Pires, vulgo "Três Pedaços" em 1927. APEB: Seção Judiciária, est. 39, cax.1402, doc.3, 1927, p. 12.
} 
Para Todos" foi preso e conduzido para esta delegacia; que absolutamente não offendeu a José Raymundo dos Santos.

Nos autos foram ouvidos três testemunhas que a João Francisco Pires dão a autoria do ferimento que José Raymundo dos Santos apresentou. ${ }^{29}$

O depoimento não informou o tipo de discussão que ocorreu entre Três Pedaços e o seu conhecido Mata Escura, seria importante, pois este era também um famoso capoeira da "velha Bahia" e poderia oferecer outros elementos para melhor entendermos o que de fato ocorreu naquela noite. ${ }^{30}$

Por mais que o capoeira Três Pedaços tenha negado as ofensas físicas ao espanhol José Raymundo dos Santos, nos autos foram ouvidas três testemunhas que a ele deram a autoria. Entretanto, o exame de corpo de delito realizado negou todas as acusações feitas ao réu, livrando-o de ser incurso no art. 303 do Código Penal, que punia o crime de lesões corporais:

Não encontro nos autos caracterisado o delicto capitulado no artigo 303 do código penal.

Por isso deixo de offerecer dennuncia contra o indiciado de nome João Francisco Pires.

Assim procedo, porque, não há prova directa do crime previsto no artigo 303.

Submettido o paciente de nome José Raymundo dos Santos a exame medico legal (...). "Verificaram os peritos tratar-se de um" "rapaz de boa constituição, sem vícios" "apparentes de conformação esquelética", "accusando ter recebido forte traumatismo na região dorsal, não encontrando, entretanto, os peritos nessa ou n'outra qualquer parte do corpo, o menor signal traumático pathologico". (...).

Em resposta ao primeiro quesito do laudo de exame medico legal: si ouve ferimento ou offensa phísica responderam os legistas - negativamente offender produzindo dôr, ou offender produzindo lesão são os dois modos pelos quais se extrema o delicto capitulado no artigo 303.

A dor, no caso em apreço, é o próprio crime, e o crime não se presume - Ora o corpo de delicto directo affirma que não houve "ferimento nem offensa physica", logo penso que não há acto delictuoso a punir. (...) assim sendo, opino pelo archivamento destes autos. ${ }^{31}$

Neste período, a polícia técnica tinha um importante papel no processo investigativo do crime. O laudo médico era o documento que geralmente definia um inquérito que tratava de crime de lesão corporal, portanto era anexado aos autos do processo. Foi justamente este documento que inocentou Chico Três Pedaços. Assim, em 29 de agosto de 1927, a promotoria decidiu arquivar o processo movido contra o capoeira. Entretanto, o réu continuou preso por mais algum tempo, até que o Major Cosme de Farias intercedesse por ele.

\footnotetext{
${ }^{29}$ Idem.

${ }^{30}$ Sobre o capoeira Mata Escura, ver REGO, Waldeloir. Capoeira angola... Op. cit.

31 Processo crime movido contra João Francisco Pires, vulgo "Três Pedaços" em 1927. Op. cit., p.13. O excesso de aspas e as palavras grifadas constam no documento.
} 
Illm. Sn $\mathrm{D}^{\mathrm{r}}$ Juiz Substituto da $1^{\text {a }}$ Vara Crime.

Cosme de Farias, defensor de João Francisco Pires, preso na Casa de Detenção, desde julho ultimo, á disposição de v. s., sabendo que o processo instaurado contra o paciente fora mandado archivar pelo representante da Justiça Publica requer assim, que v. s. ordene a soltura do paciente, visto ser illegal o constrangimento que o mesmo soffre. Soliscito dispensa de sella por se tratar de um desvalido e confiado na rectidão da justiça de v. s.

P. deferimento

Bahia, 30 de Setembro de 1927.

Cosme de Farias ${ }^{32}$

A intervenção de Cosme de Farias garantiu a liberdade de João Francisco Pires. Dentre os vários recursos de retórica utilizados pelo rábula, como já foi referido, eis aqui um exemplo, no qual o defensor sensibilizou o "representante da Justiça Pública", lembrando que o réu já havia sido absolvido e que continuando preso sofria constrangimento por parte da lei e da justiça. Argumentava que Três Pedaços já não representava perigo algum, pois se tratava de um "desvalido e confiado na rectidão da justiça" daquela autoridade.

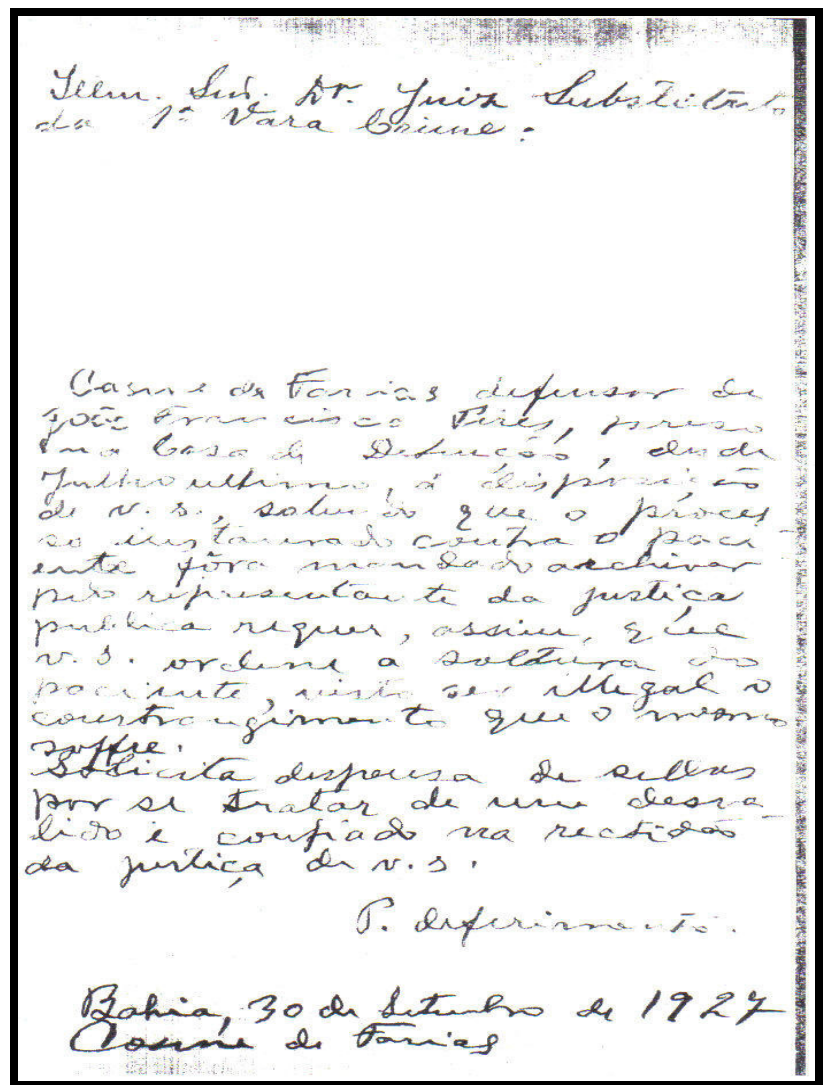

Fac-simile do original do pedido de soltura (P. deferimento) em favor do capoeira Chico Três Pedaços, assinado pelo Major Cosme de Farias, disponível no Arquivo Público do Estado da Bahia Seção Judiciária.

\footnotetext{
32 Ofício encontrado em anexo ao referido processo movido contra o capoeira Chico Três Pedaços, em 1927.
} 
Encontrei no Arquivo Público do Estado da Bahia 4 processos movidos contra Chico Três Pedaços, sendo um por furto e os três restantes por lesões. Além deste o Major Cosme de Farias é citado em um outro movido contra Três Pedaços no ano de 1923. O capoeira foi denunciado pelo promotor público da $2^{\mathrm{a}}$ Circunscrição Criminal por ter ferido a navalha o praça de polícia Ludgero Alves de Sant' Anna. ${ }^{33}$

Neste processo, Três Pedaços é identificado como tendo vinte e um anos de idade e trabalhar como carregador. Entretanto, sua saga de desordeiro no universo das ruas de Salvador era antiga. Em 1914 já era conhecido por tal apelido e faquista perigoso:

Foi preso hontem, à noite, no $1^{\circ}$ districto de Brotas, armado de faca de ponta, o indivíduo João Francisco Pires, vulgo Três Pedaços. O faquista é desordeiro conhecido da polícia e foi recolhido a estação policial do districto. ${ }^{34}$

Se em 1914 Três Pedaços já era um desordeiro afamado, então parece ter começado cedo em suas práticas de capadoçagem. Três Pedaços na verdade fazia parte de uma galeria de capoeiras que viveram na primeira metade do século $\mathrm{XX}$, muitos dos quais tendo alcançado a capoeiragem do século XIX, sobre a qual os historiadores ainda não foram presenteados com documentação histórica um tanto quanto satisfatória. Até o então a pesquisa histórica sobre a capoeira na Bahia só conseguiu alcançar de forma mais precisa e documentada as primeiras décadas do século XX, identificando a prática da capoeira no universo da criminalidade das ruas, e por essa razão os processos criminais se caracterizar fonte potencial para os estudos da capoeira baiana neste período. Entretanto, muito poderá ainda ser revelado sobre os bastidores das relações sociais que envolviam os agentes de uma das mais simbólicas práticas da diáspora africana no Brasil, por conseguinte na Bahia.

\section{Para concluir: a guisa de provocações}

Bastião, Chico Três Pedaços e Pedro Porreta, obviamente não foram os únicos agentes culturais da capoeiragem baiana a serem defendidos pelo rábula Cosme de Farias. Somam-se a estes: Samuel da Calçada, Nozinho da Cocheira e possivelmente os irmãos Duquinha e Scalvino. Muitos desses capoeiras eram apontados como capangas de líderes políticos partidários de Cosme de Farias, entre eles os ex-governadores Joaquim José de Seabra e Antônio Moniz assim como o ex-secretário de Segurança Pública José Álvaro Cova, o qual o Mestre Noronha apontava como "padrinho dos capoeiras". ${ }^{35}$ Teriam essas

\footnotetext{
33 Processo crime movido contra João Francisco Pires, em 1923. APEB: Seção Judiciária, Est. 214, cx. 48, doc. 10 .

${ }^{34}$ Diário de Notícias, 04/07/1914, p. 3. Por faquista entende-se "pessoa que usa de faca como arma ofensiva". FERREIRA, Aurélio Buarque de Holanda. Pequeno dicionário da lingua portuguesa - ilustrado. Op. Cit.

${ }^{35}$ COUTINHO, Daniel. O abc da capoeira angola: os manuscritos do mestre Noronha. Brasília: CIDOCA, 1993, p. 61.
} 
filiações políticas alguma relação com a participação de Cosme de Farias nos processos movidos contra os referidos capoeiras? O velho rábula teve uma história de ativismo social que não se deve negar, o que justificaria o seu empenho em livrar os capoeiras das malhas da justiça, mesmo aqueles apontados como capangas do grupo seabrista. Pois caros leitores, aguardemos por novos aventureiros que estejam dispostos a vasculhar a documentação histórica para que possa ser revelado de forma mais precisa esse aspecto dos bastidores da história dos valentes capoeiras da capital baiana, por enquanto apostaremos na idéia de que assim como Manoel Rosentino, o Major Cosme de Farias adorava o capadócio da Bahia.

\section{Referências bibliográficas}

1. ABREU, Frederico José de. Bimba é bamba: a capoeira no ringue. Salvador: Instituto Jair Moura, 1999.

2. CELESTINO, Mônica. "Cosme de Farias: advogado dos pobres". In: Memórias da Babia. Salvador: Empresa Baiana de Jornalismo S. A., 2002, v. 1.

3. CELESTINO, Mônica. Réus, analfabetos, trabalhadores e um Major - a inserção política e social do parlamentar Cosme de Farias em Salvador. Salvador: UFBA, 2005. Dissertação de Mestrado.

4. COUTINHO, Daniel. $O$ abc da capoeira angola: os manuscritos do mestre Noronha. Brasília: CIDOCA, 1993.

5. DIAS, Adriana Albert. Mandinga, manha \& malícia: uma história sobre os capoeiras na capital da Babia (1910-1925). Salvador: EDUFBA, 2006.

6. FERREIRA, Aurélio Buarque de Holanda. Pequeno dicionário brasileiro da língua portuguesa - Ilustrado. 11 ed. Rio de Janeiro: Gama/Civilização Brasileira, 1971.

7. MOURA, Jair. "A sinonímia popular da capoeiragem". In: Capoeira: ginástica da resistência. Revista da Babia, v. 32, no 33, Julho de 2001, p. 85.

8. OLIVEIRA, Josivaldo Pires. No tempo dos valentes: os capoeiras na cidade da Babia. Salvador: Quarteto, 2005.

9. PASTINHA, Mestre. Capoeira Angola. Salvador: Fundação Cultural do Estado da Bahia, 1988.

10. PIRES, Liberac Cardoso Simões. A capoeira na Babia de Todos os Santos: um estudo sobre cultura e classes trabalhadoras (1890-1937). Tocantins: NEAB/ Grafset, 2004.

11. QUERINO, Manoel. Babia de outrora. Salvador: Livraria Econômica, 1916.

12. REGO, Waldeloir. Capoeira angola: ensaio sócio-etnográfico. Salvador: Itapoã, 1968.

13. SAFFIOTI, Heleieth I. B. O poder do macho. São Paulo: Moderna, 1987.

\section{JORNAIS}

Jornal de Notícias (dezembro de 1914)

Diário de Notícias (julho de 1914)

Gažta do povo (fevereiro e março de 1915)

\section{DOCUMENTOS JUDICIÁRIOS}

Processo crime movido contra Pedro Celestino dos Santos, vulgo "Pedro Porreta", em 1931. APEB: Seção Judiciária: Est. 210, cx. 220, doc. 1. 
Processo crime movido contra João Francisco Pires, vulgo "Três Pedaços" em 1927. APEB: Seção Judiciária, est. 39, cax.1402, doc.3, 1927.

Processo crime movido contra João Francisco Pires, em 1923. APEB: Seção Judiciária, est. 214, cx. 48, doc. 10. 